\title{
Cholinergic Basal Forebrain Neurons Project to Cortical Microvessels in the Rat: Electron Microscopic Study with Anterogradely Transported Phaseolus vulgaris Leucoagglutinin and Choline Acetyltransferase Immunocytochemistry
}

\author{
Elvire Vaucher and Edith Hamel \\ Laboratory of Cerebrovascular Research, Neurobiology Unit, Montreal Neurological Institute, McGill University, \\ Montréal, Québec, Canada H3A 2B4
}

Physiological evidence indicates that central cholinergic pathways are involved in the regulation of cerebral cortical blood flow. We investigated the possible contribution of basal forebrain cholinergic neurons from the substantia innominata $(\mathrm{SI})$ to the innervation of cortical microvessels. Basalo-cortical perivascular nerve terminals were detected by light and electron microscopic immunocytochemistry of anterogradely transported Phaseolus vulgaris leucoagglutinin (PHA-L) following its injection in the SI, and were compared to cortical perivascular cholinergic (immunoreactive for choline acetyltransferase (ChAT)) terminals. The basal forebrain origin of cholinergic terminals was evaluated after unilateral ibotenic acid lesion of the SI. PHA-L varicose fibers reached and surrounded microvessels in all cortical subdivisions examined. When studied at the ultrastructural level in the fronto-parietal and perirhinal cortices, perivascular PHA-L nerve terminals were located significantly closer to microvessels in the fronto-parietal than in the perirhinal cortex (respective average distance of $0.98 \pm$ 0.09 and $1.34 \pm 0.07 \mu \mathrm{m} ; p<0.01$ ). PHA-L and ChAT terminals in the fronto-parietal cortex compared very well in their perivascular distribution but not in the perirhinal cortex. In both cortices, perivascular PHA-L terminals were similar in size to, but engaged more frequently in synaptic contacts than their ChAT counterparts. Following SI lesion, the density of cortical ChAT terminals including those reaching microvessels decreased significantly (56 and $63 \%$, respectively, $p<0.005$ ) in the fronto-parietal cortex, while the cortical and perivascular denervations were much less pronounced $(26 \%$, not significant and $35 \%, p<$ 0.05 , respectively) in the perirhinal cortex. These results indicate that basal forebrain neurons project preferentially to fronto-parietal cortical microvessels and further show that a significant proportion of these projections are cholinergic. In addition, the difference in distribution and/or

\footnotetext{
Received Apr. 6, 1995; revised July 11, 1995; accepted July 14, 1995.

This work was supported by a grant (MA-9967) and a Scientist Award from the Medical Research Council of Canada (E.H.), as well as a Studentship (E.V.) from Le Ministère de la Recherche et de l'Espace. France. We are most grateful to Lyne Grégoire for technical assistance, Linda Michel for preparation of the manuscript and Dr. B. K. Hartman (University of Minnesota, Minneapolis, MN) for a generous gift of the ChAT antibody.

Correspondence should be addressed to Edith Hamel, Ph.D., Laboratory of Cerebrovascular Research, Montreal Neurological Institute, 3801 University Street, Moniréal, Québec, Canada H3A 2B4

Copyright 1995 Society for Neuroscience $0270-6474 / 95 / 157427-15 \$ 05.00 / 0$
}

synaptic incidence between perivascular PHA-L and ChAT terminals suggested that noncholinergic SI neurons also contribute to these neurovascular associations, and more so in the perirhinal cortex, as further indicated by the lesion studies. Such finding corroborates recent physiological evidence for a functional innervation of the cortical microvascular bed by $\mathrm{SI}$ neurons, a role that might be relevant to the overall pathology of Alzheimer's dementia.

[Key words: Phaseolus vulgaris leucoagglutinin (PHA-L), choline acetyltransferase (ChAT) immunocytochemistry, acetylcholine, basal forebrain, substantia innominata, cerebral blood vessels, cerebral blood flow, ultrastructure]

The cholinergic innervation of the neocortex has been extensively studied and its main origin identified as the nucleus basalis of Meynert in primates or its equivalent, the substantia innominata (SI) in the rat (Divac et al., 1975; Mesulam et al., 1983; Rye et al., 1984; Woolf et al., 1991). Numerous studies have provided evidence for the involvement of these cholinergic neurons in cognitive functions and in processes of arousal and attention, with their degeneration being a landmark characteristic of Alzheimer's dementia (Coyle et al., 1983; Bartus et al., 1985). In the rat, electrical or chemical stimulation of the SI has further been shown to result in considerable increases in cerebral blood flow in various cortical arcas but prominently so in the frontal and parietal cortices (Lacombe et al., 1987, 1989; Arnerić, 1989; Biesold et al., 1989; Adachi et al., 1990a,b; and for a recent review, see Sato and Sato, 1992). These blood flow changes are accompanied by a local release of acetylcholine ( $\mathrm{ACh}$ ) (Kurosawa et al., 1989) and involve muscarinic (Dauphin et al., 1991) and/or nicotinic (Linville et al., 1993b) ACh receptors. Moreover, they appear to be independent from cortical interneurons (Linville et al., 1993a) and from pial vessels dilatation (Adachi et al., 1992b). Altogether, these data strongly suggested that the flow changes can be elicited by a direct action of the SI neurons on the cortical microvessels in order to control, locally, blood supply to cortical areas.

Using a double-immunofluorescence approach, we recently showed that a subset of intracortical bipolar cholinergic neurons, also immunoreactive for vasoactive intestinal polypeptide (VIP), were engaged in neurovascular associations with cortical microvessels (Chédotal et al., 1994a). However, the origin (intracortical and/or basal forebrain) of the vast majority of perivascular cholinergic fibers could not be established. The cholinergic neurons from the SI would appear as the best candidates for this 
innervation as their lesioning has been shown to result in re ductions in basal cortical blood flow (Gomi et al., 1991; Peruzzi et al., 1993). Yet, lesion of these neurons reportedly does not impede choline acetyltransferase (ChAT) activity associated with cortical microvessels (Galea et al., 1991), excluding somehow a direct projection to cortical microvessels. These findings are rather surprising in view of previous anatomical reports demunstrating intimate relationships between cholinergic nerve terminals and cortical blood vessels (Eckenstein and Baughman, 1984; Arnerić et al., 1988; Chédotal et al., 1994a,b) or documenting the loss of the perivascular neural plexus (believed to originate in part from the nbM) from brain cortical microvessels in Alzheimer's disease (Scheibel et al., 1987; de la Torre and Mussivand 1993).

The aim of the present study was thus to assess the possibility that SI neurons contribute to the cholinergic innervation of the cortical microcirculation. To this end, we performed microiontophoretic injections of the anterograde tracer Phaseolus vulgaris leucoagglutinin (PHA-L) in the SI and determined, at the ultrastructural level and in two cortical subdivisions exhibiting distinct vasomotor responses to SI stimulation (Vaucher et al., 1995), whether PHA-L-labeled nerve terminals originating from SI neurons reach intracortical microarterioles and capillaries. In order to infer cholinergic specificity to perivascular $\mathrm{PHA}-\mathrm{L}$ nerve terminals, their surface area and distance from the blood vessel wall were compared to those of perivascular cholinergic terminals in the same cortical area. Furthermore, the effects of unilateral SI lesion on cortical perivascular cholinergic terminals were investigated. The results show that SI neurons project preferentially to fronto-parietal cortical microvessels and that the bulk of perivascular cholinergic projections in this area originates in the basal forebrain.

Some of these data have appeared in abstract form (Vaucher and Hamel, 1994).

\section{Materials and Methods}

\section{Animals}

Male Sprague-Dawley rats, weighing 300-320 gm (Charles River, Montréal, Canada), were housed in a temperature-controlled $\left(21-25^{\circ} \mathrm{C}\right.$ ) room, under natural daylight conditions and had free access to food and water. All experiments were approved by the Animal Ethics Committee based on the guidelines of the Canadian Council on Animal Care.

\section{Surgical procedures}

PHA-L injection in the SI. Animals $(n=3)$ were anesthetized with a mixture of ketamine $(35 \mathrm{mg} / \mathrm{kg}$, i.m., Ayerst, Montréal, QC, Canada) and xylazine (Rompun, $2 \mathrm{mg} / \mathrm{kg}$, i.m., Haver, Etobicoke, ON, Canada) and mounted in a Kopf stereotaxic 900 frame adjusted to the coordinate system of Paxinos and Watson (1986) except that the incisor bar was set at $-5 \mathrm{~mm}$. PHA-L (Vector Laboratories, Burlingame, CA) was microinfused in a $2.5 \%$ solution in $10 \mathrm{~mm}$ sodium-phosphate buffer (NaPBS, pH 8.0) through a glass micropipette with a tip diameter of $20-30 \mu \mathrm{m}$. The pipette was stereotaxically lowered in the left SI and four injection sites (see below) were performed in order to increase the volume of injection. The tracer was iontophoretically injected with a 8-10 $\mu$ A positive current delivered by a $7 \mathrm{sec}-\mathrm{on} / 7 \mathrm{sec}$-off pulse for 25 min (Gerfen and Sawchenko, 1984). Pipets were left in place for $5 \mathrm{~min}$ before removal from the brain in order to avoid diffusion and were changed between each injection. The coordinates of the four injection sites were as follows [anterioposteriority (AP) and laterality (L) from bregma, verticality (V) below the skull surface, in $\mathrm{mm}$ ): AP: $-0.9, \mathrm{~L}$ : $-2.7, \mathrm{~V}:-7.6$; AP: -1.4 , L: $-2.8, \mathrm{~V}:-7.9$; AP: $-1.3, \mathrm{~L}:-3.3$, V: -7.9 ; AP: $-1.8, \mathrm{~L}:-3.1, \mathrm{~V}:-8.0$ (Fig. 1 ). The tracer was allowed to migrate for $14 \mathrm{~d}$ before the animals were processed for PHA-L immunocytochemistry.

Ibotenic acid injection in the SI. Rats $(n=5)$ were anesthetized and stereotaxically prepared as above. A glass micropipette with a tip di- ameter of $50 \mu \mathrm{m}$ was inserted twice in the left $\mathrm{SI}$ at the following coordinates $(\mathrm{mm})$ : AP: $-0.9,-1.8 ; \mathrm{L}:-2.7,-2.9 ; \mathrm{V}:-7.6,-7.9$ below the skull surface. Ibotenic acid $(10 \mu \mathrm{g}$ in $1 \mu \mathrm{l}$ of PBS $10 \mathrm{~mm}$. pH 7.4; Sigma, St.Louis, MO) was slowly injected $(0.1 \mu \mathrm{l} / \mathrm{min}, 5 \mathrm{~min} /$ site) through the micropipette connected to a $10 \mu \mathrm{l}$ Hamilton syringe (Hamilton $1801 \mathrm{NE}$, Switzerland) driven by a microperfusor (pump 22 , Harvard Apparatus, MA). To avoid diffusion of the neurotoxin along the pipette's track, the pipette was left in the same position 4-5 min before its removal from the brain. The rats were allowed to survive $7-$ $10 \mathrm{~d}$ after injection of the neurotoxin and then used for choline acetyltransferase (ChAT) immunocytochemistry.

\section{Immunocytochemistry}

PHA-L immunocytochemistry. Following deep anesthesia of the rats with Somnotol $(0.1 \mathrm{mg} / 100 \mathrm{gm}$ body weight), the brains were fixed by perfusion through the ascending aorta with $500 \mathrm{ml}$ of $4 \%$ paraformaldehyde and $0.06 \%$ glutaraldehyde in $0.1 \mathrm{M} \mathrm{NaPB}(\mathrm{pH} 7.2-7.4$ ) followed by $1000 \mathrm{ml}$ of $4 \%$ paraformaldehyde alone. The brains were removed and postfixed in the latter solution for $2 \mathrm{hr}$ and then cut at the level of the fronto-parictal or perirhinal cortex (Paxinos and Watson, 1986) in coronal thick $(40-60 \mu \mathrm{m})$ sections on an Oxford Vibratome.

For light microscopic (LM) examination, sections were preincubated $1 \mathrm{hr}$ at room temperature in $20 \mathrm{~mm}$ potassium phosphate-buffered saline (KPBS, pH 7.4) containing $0.25 \%$ Triton X-100, $0.2 \%$ gelatin, and $0.001 \%$ azide. Free-floating sections were then incubated for $48 \mathrm{hr}$ at $4{ }^{\circ} \mathrm{C}$ with a biotinylated goat anti-PHA-L antibody $(1: 250$. Vector Laboratories, Burlingame, CA) followed by a $1 \mathrm{hr}$ incubation with an avidin biotin complex (ABC Elite 1:50, Vector Labs). After each incubation step, rinses were carried out in KPBS containing $0.25 \%$ Triton $(4 \times 8$ min). The final rinse was done in Tris $\mathrm{HCl}$ buffer $(0.1 \mathrm{M}, \mathrm{pH} 7.4)$. The immunocytochemical reaction product was developed in $0.05 \%$ of $3,3^{\prime}$ diaminobenzidine tetrachloride (DAB, Sigma) containing $0.03 \%$ ammonium sulfate nickel and $0.005 \% \mathrm{H}_{2} \mathrm{O}_{2}$. Sections were mounted onto gelatin-coated slices, dehydrated, and coverslipped with Permount.

For electron microscopy (EM), sections were first cryoprotected by incubation $(15 \mathrm{~min})$ in a $0.1 \mathrm{M}$ Tris-sodium metabisulfite solution $(\mathrm{pH}$ 7.4) containing $36 \%$ sucrose and $14 \%$ glycerol and then frozen (15 sec) in isopentane at $-50^{\circ} \mathrm{C}$. They were immediately thawed in NaPB and processed for immunocytochemistry as described above for LM, except that the solutions were devoid of Triton $X-100$. Sections were then rinsed in $0.1 \mathrm{M} \mathrm{NaPB}$ and postfixed for $1 \mathrm{hr}$ in $2 \%$ osmium tetroxide NaPB solution containing $7 \%$ dextrose ( $\mathrm{pH} 7.2)$. After being washed for $20 \mathrm{~min}$ in $0.1 \mathrm{M} \mathrm{NaPB}$, sections were stained en bloc with $2 \%$ uranyl acetate before dehydration and flat embeding in Araldite 502 (JBEM Services, Canada) for $48 \mathrm{hr}$ at $60^{\circ} \mathrm{C}$. After observation under the LM, areas of the fronto-parietal or perirhinal cortex were selected and reembeded in blocks of araldite. Serial thin (pale gold; $90 \mathrm{nM}$ ) or semithin (2-3 $\mu \mathrm{m}$ ) sections were cut on a Reichert-Jung Ultracut microtome. Semithin sections were mounted onto slices and observed under a Leitz Aristoplan light microscope (see below). Thin sections were collected on copper grids, double stained with uranyl acetate and lead citrate, and then examined under a JEOL CX100II electron microscope.

ChAT immunocytochemistry. The detailed protocol for ChAT immunocytochemistry at the LM and EM level has been published elsewhere (Chédotal et al., 1994b). Briefly, rat brains $(n=3)$ were fixed by perfusion, vibratome-cut coronal sections obtained, cryoprotected, and freeze-thawed as described above for PHA-L immunocytochemistry. Sections were then incubated overnight with a monoclonal mouse anti-ChAT antibody $(2 \mu \mathrm{g} / \mathrm{ml}$ in NaPBS; kindly provided by Dr. B. K. Hartman), followed by a biotinylated horse anti-mouse $\operatorname{IgG}(1: 200,1$ $\mathrm{hr}$, Vector Laboratories), and the ABC complex (1 hr). The immunocytochemical product was developed with $\mathrm{DAB}-\mathrm{Ni}+$ and $\mathrm{H}_{2} \mathrm{O}_{2}$. Tissue sections were then treated as above for embedding in Araldite and serial thin (perirhinal cortex) or $3 \mu \mathrm{m}$-thick semithin (rats with SI lesion) sections were obtained for analysis. For EM study, Triton X-100 was omitted from all solutions.

\section{LM analysis of PHA-L and ChAT perivascular nerve terminals}

The extent of the cortical projection areas of PHA-L-labeled SI neurons was evaluated on low magnification camera lucida drawings from brain sections obtained from rats in which the injection site (see Fig. 1) was limited to but encompassed the full extent of the SI. PHA-L immunoreactive projections in the fronto-parietal and perirhinal cortices were selected for further analysis since blood flow in these two cortical areas 


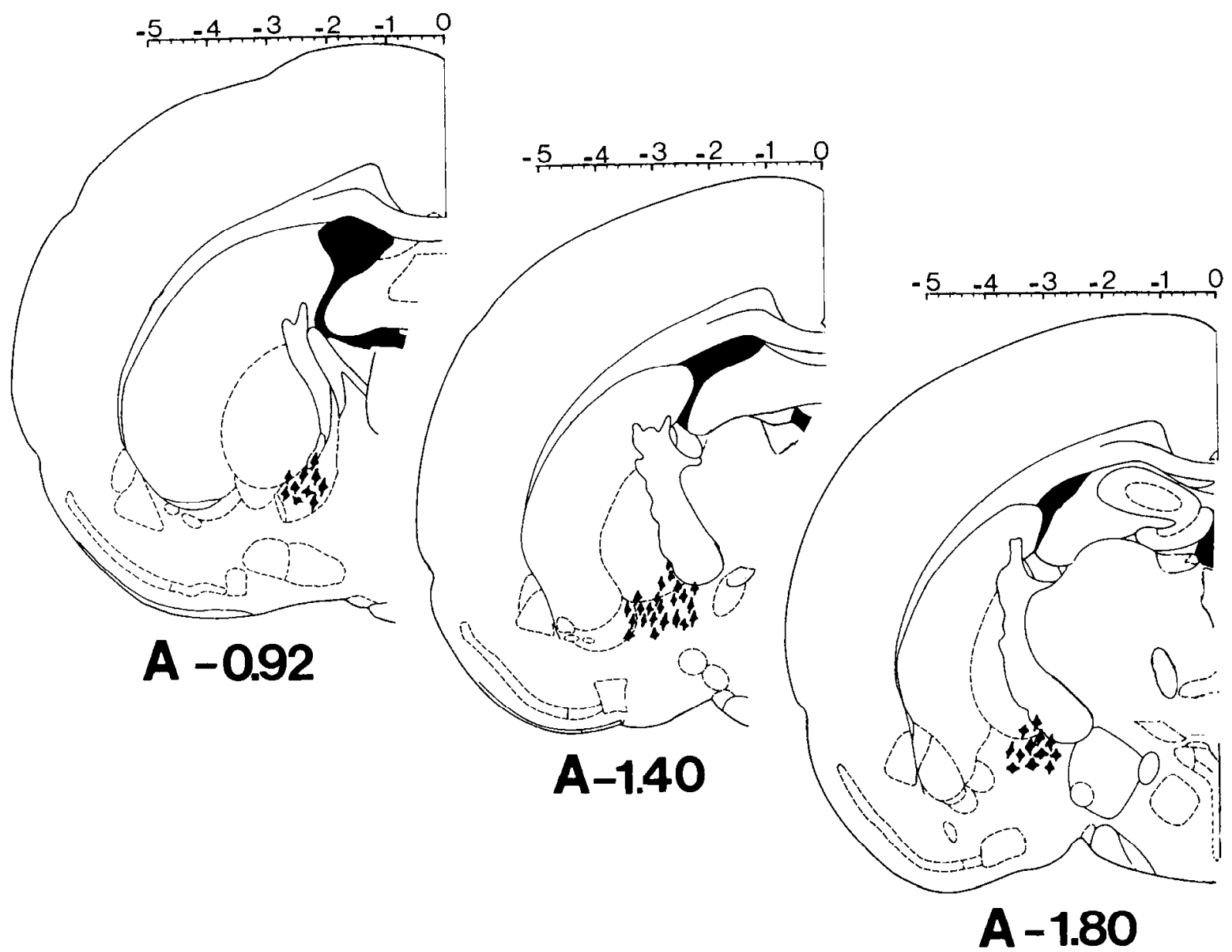

Figure 1. Location of the PHA-L injection sites reported in three coronal planes of the brain atlas at $-0.92,-1.4,-1.8 \mathrm{~mm}$ from bregma. The precise coordinates of the four injection sites located throughout the substantia innominata are given in details in Material and Methods.

was respectively increased or unaltered by stimulation of the SI (Vaucher et al., 1995). At the LM level, a nerve terminal was considered perivascular when it could be seen to follow the contours of the blood vessel walls (in vibratome sections), or when it was directly apposed to and literally touched the vessel walls (in semithin sections), as determined on photomicrographs (for more detail, see Chredotal et al., 1994b). The size (lumen diameter) of randomly selected intracortical microvessels $(n=35)$ reached by SI terminals was measured on high magnification photomicrographs of semithin sections. On similar sections from rats with unilateral SI lesion, the amounts of total and perivascular ChAT terminals were counted in a fixed area $\left(0.2 \mathrm{~mm}^{2}\right)$ of fronto-parietal and perirhinal cortices and compared by Student $t$ test between lesioned and control sides. A $p$-value $\leq 0.05$ was taken as significant. For further information, the percentage decrease of perivascular cholinergic terminals was compared to that of total cortical cholinergic terminals determined in the same cortical areas.

\section{EM analysis of PHA-L and ChAT perivascular terminals}

At the ultrastructural level, a nerve terminal was considered perivascular when it was located within a $3 \mu \mathrm{m}$ perimeter around the vessel basal lamina. This perimeter was selected from previous ultrastructural studies of functional neurovascular systems in peripheral, cerebral (Lee, 1981; Dodge et al., 1994), and small intraparenchymal (Chédotal et al., 1994b; Cohen et al., 1995) blood vessels. It was defined as the maximal distance within which $\mathrm{ACh}$ released from neuronal elements such as axon terminals might functionally influence the microcirculation either directly or through interaction with intervening processes located closer to the vessel wall. The morphometric characteristics of perivascular PHA-L and ChAT terminals were compared in both cortical subdivisions. The size (expressed in surface area) of each perivascular nerve ending and its nearest distance to the outer basal lamina of the microvessel were measured with a Bioquant II program and a MTi65 camera.
This analysis was performed on electron photomicrographs (working magnification of $14,000 \times$ ) for 91 and 130 PHA-L terminals in the fronto-parietal and perirhinal cortex, respectively, and 128 and 143 ChAT terminals in these same respective cortical areas. Data from ChAT terminals in the fronto-parietal cortex were taken from Chédotal et al. (1994b) since they were obtained in the same area and from the same experimental protocol. A comparison of the synaptic frequency of perivascular PHA-L or ChAT terminals determined in single thin sections in the fronto-parietal and perirhinal cortices was also performed. A labeled (PHA-L or ChAT) varicosity was found to establish a synaptic contact when a junctional complex on an adjacent cellular element was apparent. This could correspond to a restricted zone of parallel membrane apposition and slight enlargement of the space with or without a clear postsynaptic thickening. As an additional means of comparison between the two perivascular systems, the synaptic incidence, which gives a precise estimate for a given neurotransmitter system of the proportion of nerve terminals engaged in junctional contacts, was calculated for PHA-L and ChAT varicosities. The synaptic incidence for whole varicosities was extrapolated from the observed synaptic frequency in single thin sections, using the stereological formula of Beaudet and Sotelo (1981), which takes into account the average diameter of the varicosities, the length of their junctional complexes, and the thickness of the sections. A representative population of cortical microvessels reached by perivascular terminals was randomly selected $(n=$ 46) under electron microscopic observation. They were phorographed under appropriate magnification $(\times 2500-10,000)$ and their lumen $\mathrm{di}-$ ameter measured as described above for the sectional area of nerve endings.

Statistical comparisons between the topometric data of perivascular PHA-L and ChAT-immunolabeled nerve terminals in the various cortical areas were achieved by one-way ANOVA followed by the multiple comparison test of Tukey, a $p \leq 0.05$ was considered significant. 

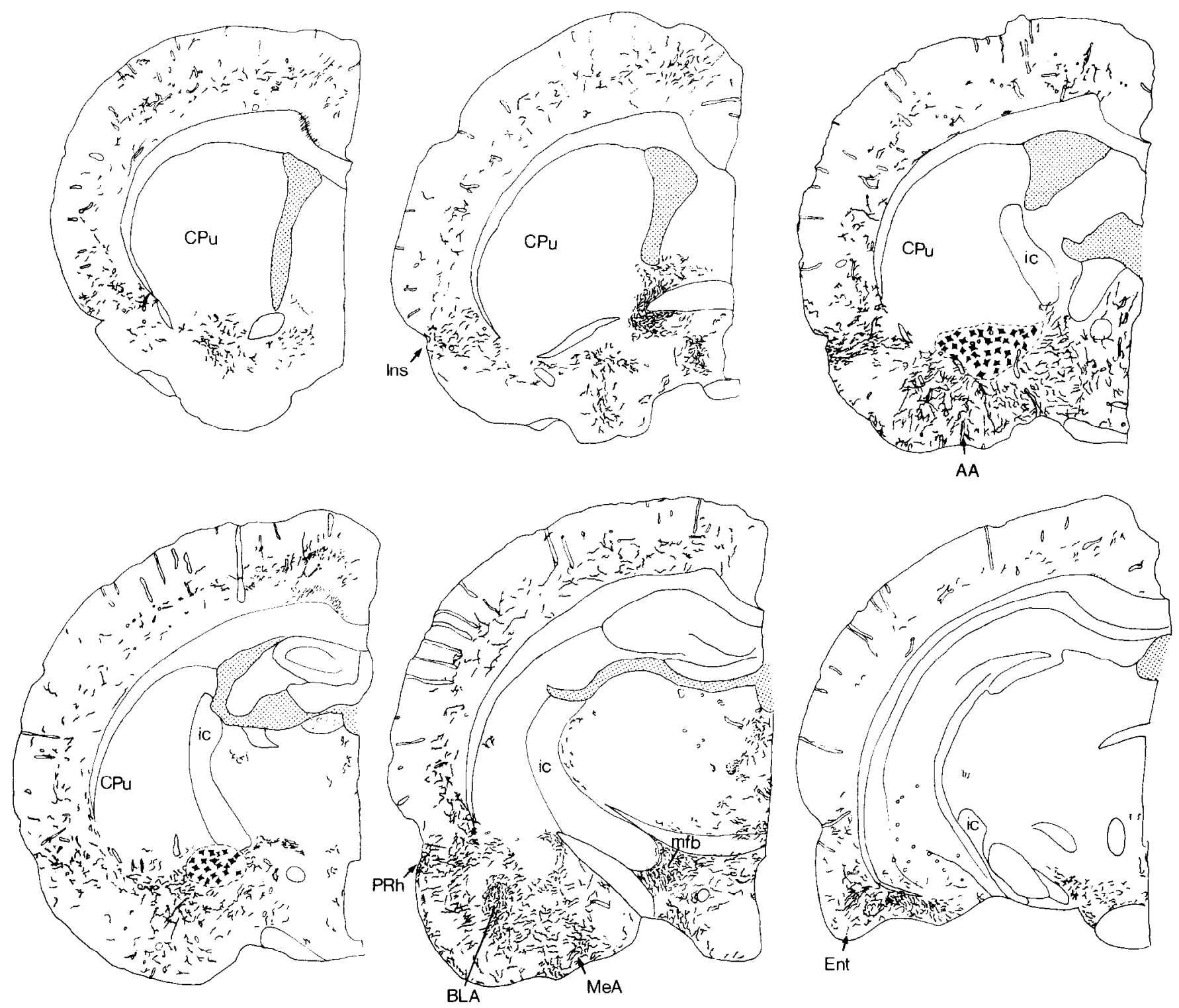

Figure 2. Camera lucida drawings of PHA-L immunoreactive fibers and labeled cell bodies (black stars) reconstructed in coronal sections from three injected rats. $A A$ : anterior amygdala; $B L A$ : basolateral amygdala; $C P u$ : Caudate putamen; Ent: entorhinal cortex; $i c:$ internal capsul; $I n s$ : insular cortex; $M e A$ : medial amygdala; $m f b$ : medial forebrain bundle; $P R h$ : perirhinal cortex.

\section{Results}

\section{PHA-L injected cells and their perivascular projections}

The area of labeled cell bodies after PHA-L injections was very similar amongst the different rats. It extended from the anterior to the posterior part of the SI in both the ventral and dorsal aspects (Fig. 1). In coronal thick sections, projection fibers immunoreactive for PHA-L could be followed for a long distance through the striatum and along the corpus callosum (not shown) before appearing in the cerebral cortex where they were fine and varicose for the most part. PHA-L fibers were distributed throughout the cortical layers in all cortical subdivisions, the majority being confined to layers IV and $\mathrm{V}$ in the frontal and parietal cortices. In contrast, a very dense plexus of PHA-L labeled fibers invaded the full extent of the insular, perirhinal, and entorhinal cortices. The density of projection fibers was greatest in the amygdala, entorhinal, perirhinal, and insular areas as compared to more moderately distributed PHA-L fibers in the fron- tal, parietal, and temporal subdivisions of the cerebral cortex, with only sparse labeling in the cingulate cortex (Fig. 2).

PHA-L fibers surrounding penetrating arteries, local microarteries as well as smaller intraparenchymal blood vessels of varying sizes (lumen diameter $\sim 5$ to $68 \mu \mathrm{m}$ ) were observed in all cortical areas examined (Fig. 3). These neurovascular associations were better defined in semithin sections (Fig. 4) where multiple PHA-L cortical varicosities were in direct apposition with both local capillaries (lumen diameter $\sim 4$ to $8 \mu \mathrm{m}, 75 \%$ of vessels) and larger microvessels including small arteries, microarterioles, and possibly veins (lumen diameter $\sim 8-30 \mu \mathrm{m}$, $25 \%$ of vessels). Some of these cortical microvessels received more than one PHA-L immunoreactive nerve terminal (Fig. 4).

\section{Ultrastructural analysis of perivascular PHA-L fibers}

Perivascular PHA-L varicosities were studied in detail at the ultrastructural level in the fronto-parietal (Fig. 5) and perirhinal 

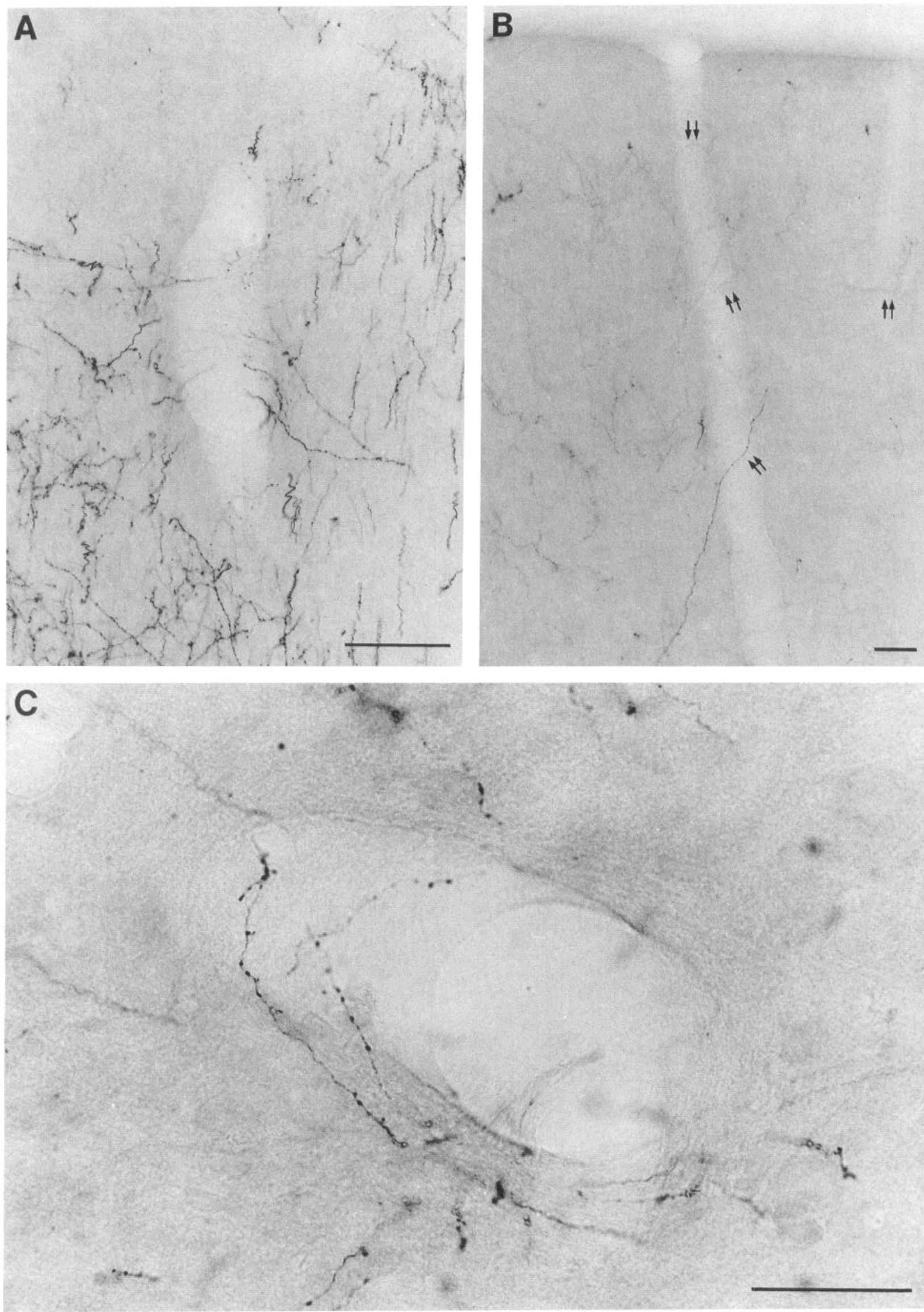

Figure 3. PHA-L immunoreactive fibers in thick sections can be seen to surround intracortical blood vessels or a small penetrating artery (double arrows in $B$ ) located in the perirhinal $(A)$, parietal $(B)$, and frontal $(C)$ cortical areas. Scale bars: $50 \mu \mathrm{m}$ 
Figure 4. PHA-L immunolabeled varicosities visualized in a semithin section $(2 \mu \mathrm{m})$ in the parietal cortex. Note the direct apposition of some varicosities to the blood vessel wall (arrows). Scale bar: $50 \mu \mathrm{m}$.

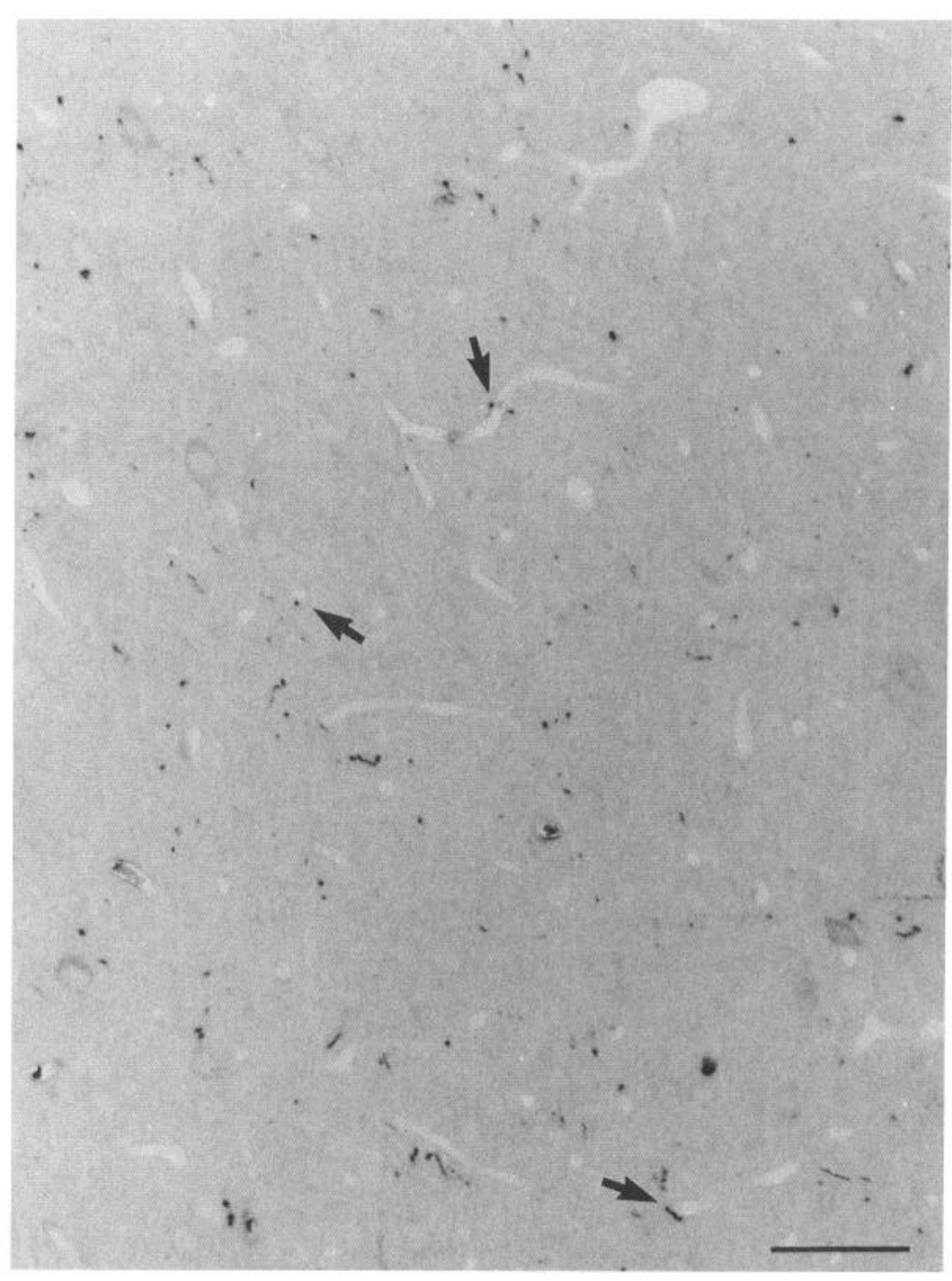

cortices (Fig. 6). Their respective repartition around the vessel wall showed that more than $60 \%$ of them were located within 1 $\mu \mathrm{m}$ from the vessel in the fronto-parietal cortex in contrast to only $36 \%$ in the perirhinal cortex, with PHA-L terminals located in the immediate vicinity $(0-0.25 \mu \mathrm{m})$ of the microvessels also being about twice as numerous in the fronto-parietal cortex (Fig. $7 A, B$, Table 1). In this cortical subdivision, perivascular PHA-L terminals decreased sharply in number as the distance from the vessel basal lamina increased while in the perirhinal cortex, perivascular terminals were rather uniformly distributed around the blood vessels (Fig. 7B). Overall, perivascular PHA-L nerve terminals in the fronto-parietal cortex were located slightly but significantly closer $(p<0.01)$ from the blood vessels than those of the perirhinal cortex (Table 1). Varicosities located in the immediate vicinity $(<0.25 \mu \mathrm{m})$ of microvessels virtually never contacted them directly since an intervening glial leaflet was normally present at the site of apposition (Figs. 5, 6, 8). In no instance were synaptic junctions established with these perivascular astrocytes. However, in single thin sections, PHA-L perivascular nerve terminals in the fronto-parietal and perirhinal cortices were seen to establish junctional contacts, often symmetrical, with adjacent dendritic branches (Fig. 6, Table 1). When extrapolated to the whole volume, the calculated synaptic incidence indicated that 23 and $28 \%$ of the perivascular PHA-L terminals established junctional contacts with adjacent neuronal elements in the fronto-parietal and perirhinal cortical subdivisions, respectively. The size of perivascular PHA-L terminals was similar in both cortical subdivisions (Table 1).

\section{Comparison of perivascular PHA-L and ChAT terminals}

The average size (surface area) of PHA-L perivascular nerve terminals in the fronto-parietal and perirhinal cortices was statistically similar to, although slightly larger than that of perivascular ChAT terminals measured in corresponding cortical area (Table 1). In both cortices, perivascular ChAT terminals were located at an average distance of about $0.9 \mu \mathrm{m}$ from the local microvessels (Table 1). While the distance from intracortical vessels compared very well between PHA-L and ChAT varicosities in the fronto-parietal cortex, perivascular PHA-L terminals in the perirhinal cortex (Fig. 8) were located further away from microvessels than their ChAT counterparts $(p<0.001$; Table 1). Also, the repartition of perivascular PHA-L and ChAT terminals around blood vessel walls was similar in the frontoparietal cortex, with about $60 \%$ of them being located within 1 $\mu \mathrm{m}$ from the basal lamina but not in the perirhinal cortex where only those containing ChAT were considerably enriched in the vicinity of the microvessels (Figs. 5, 7, Table 1). The synaptic frequency of perivascular ChAT varicosities on single thin sec- 

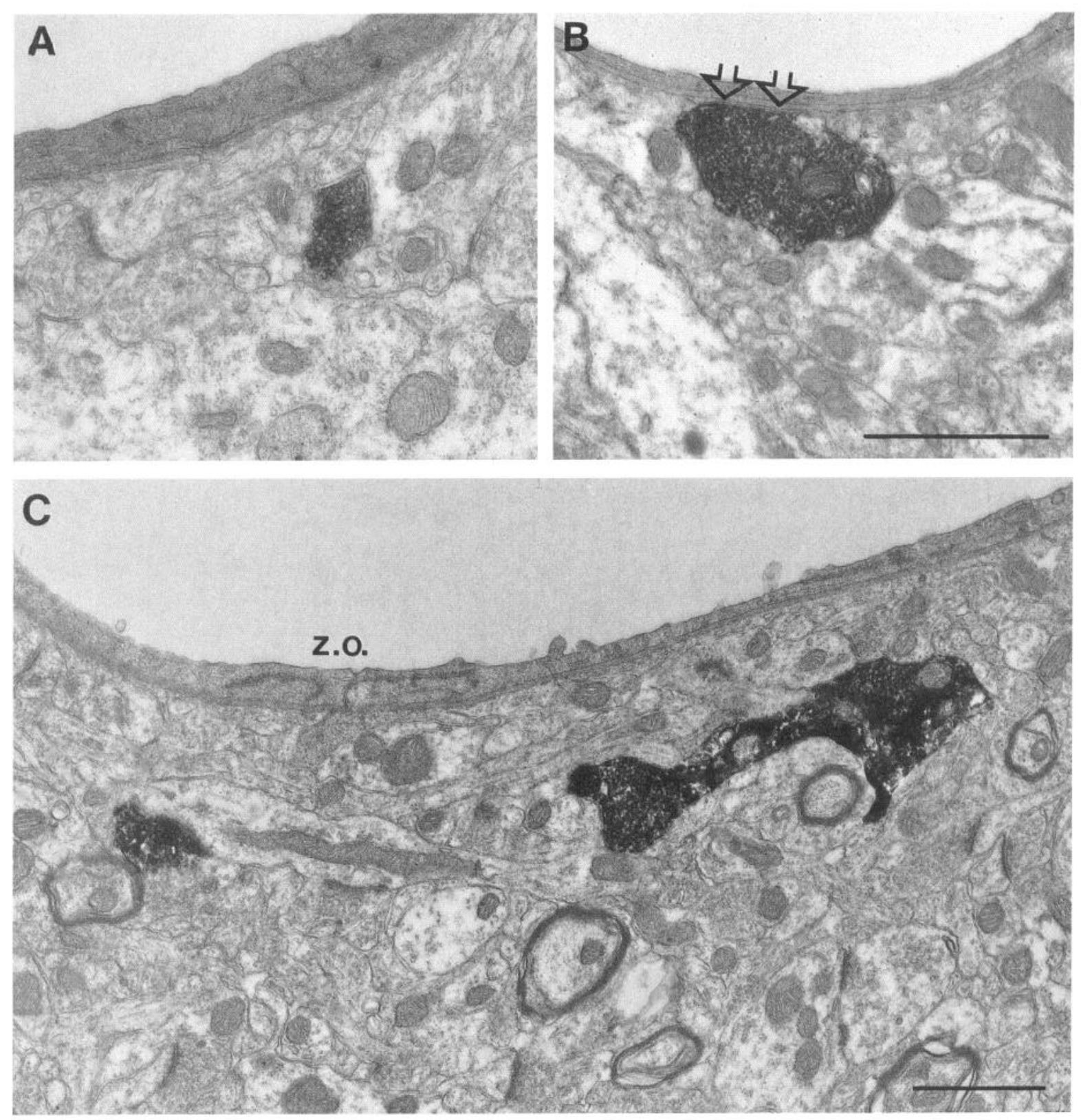

Figure 5. Perivascular PHA-L-immunolabeled terminals in the fronto-parietal cortex. $A$, This small varicosity is located in the neuropile at less than $1 \mu \mathrm{m}$ from the basal lamina of the capillary like most (62\%) PHA-L frontoparietal terminals. $B$, Terminals in the immediate vicinity of the vessel wall are generally separated from it by an astrocytic leaflet (open arrows). C, PHA-L can also be detected in axonal segments running along the vessel wall. Note the zonulae occludens (z.o.) between two endothelial cells. Scale bars: $1 \mu \mathrm{m}$.

tions was similar in the two cortical areas $(\sim 5 \%)$, but was slightly lower than that of their corresponding perivascular PHA-L terminals (Table 1). These contacts were generally small, symmetrical, and on dendritic branches and a synaptic incidence in the order of $10-15 \%$ was obtained for cholinergic terminals in both cortices (Table 1). The size of the vessels targeted by PHA-L nerve endings was similar to that reached by cholinergic terminals and accounted for local capillaries (lumen diameter between 4 to $8 \mu \mathrm{m}$ ) in $63 \%$ of cases with the remaining terminals approaching larger vessels $(8-15 \mu \mathrm{m} ; 24 \%)$ and small arteries $(15-30 \mu \mathrm{m} ; 13 \%)$.

\section{Lesion of the substantia innominata}

The efficacy of the lesion was evaluated by comparison of ChAT immunolabeled cell bodies area between the lesion and the con- trol sides. On the lesioned side, neurons containing ChAT immunoreactivity had largely disappeared from the SI and the nucleus basalis magnocellularis while those in the horizontal limb of the diagonal band of Broca were consistently spared (Fig. 9). The density of ChAT terminals in the fronto-parietal and perirhinal cerebral cortices was reduced in the hemibrain ipsilateral to the lesion, but the denervation was much more pronounced in the fronto-parietal cortex (Table 2). Similarly, perivascular ChAT terminals decreased drastically on the lesion side in the fronto-parietal cortical subdivision but only partially in the perirhinal cortex (Table 2, Fig. 9). The results also indicated comparable decreases in perivascular and neuronal ChAT terminals within the same cortical area (Table 2). The quantitative analysis performed on semithin sections from the control sides further 

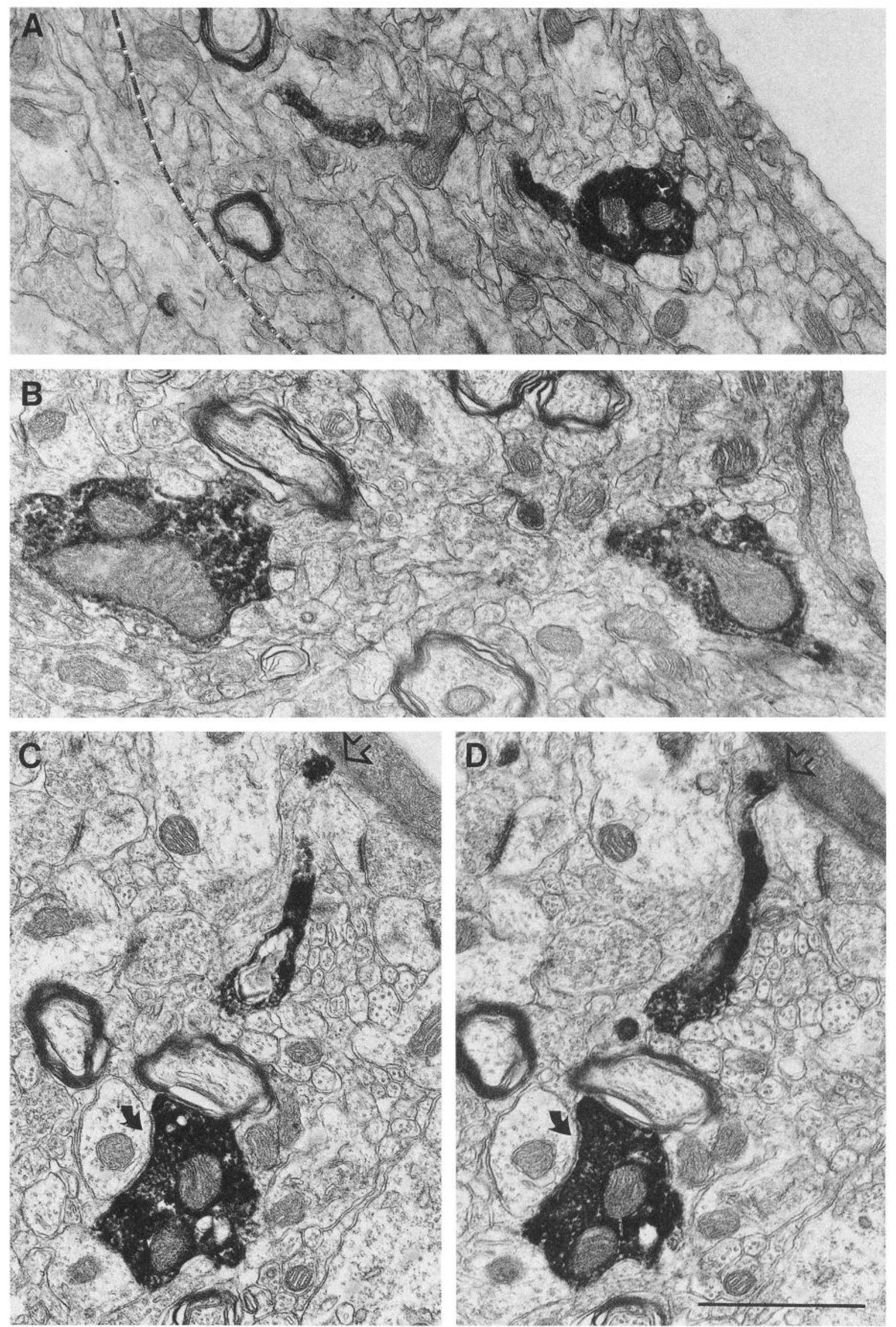

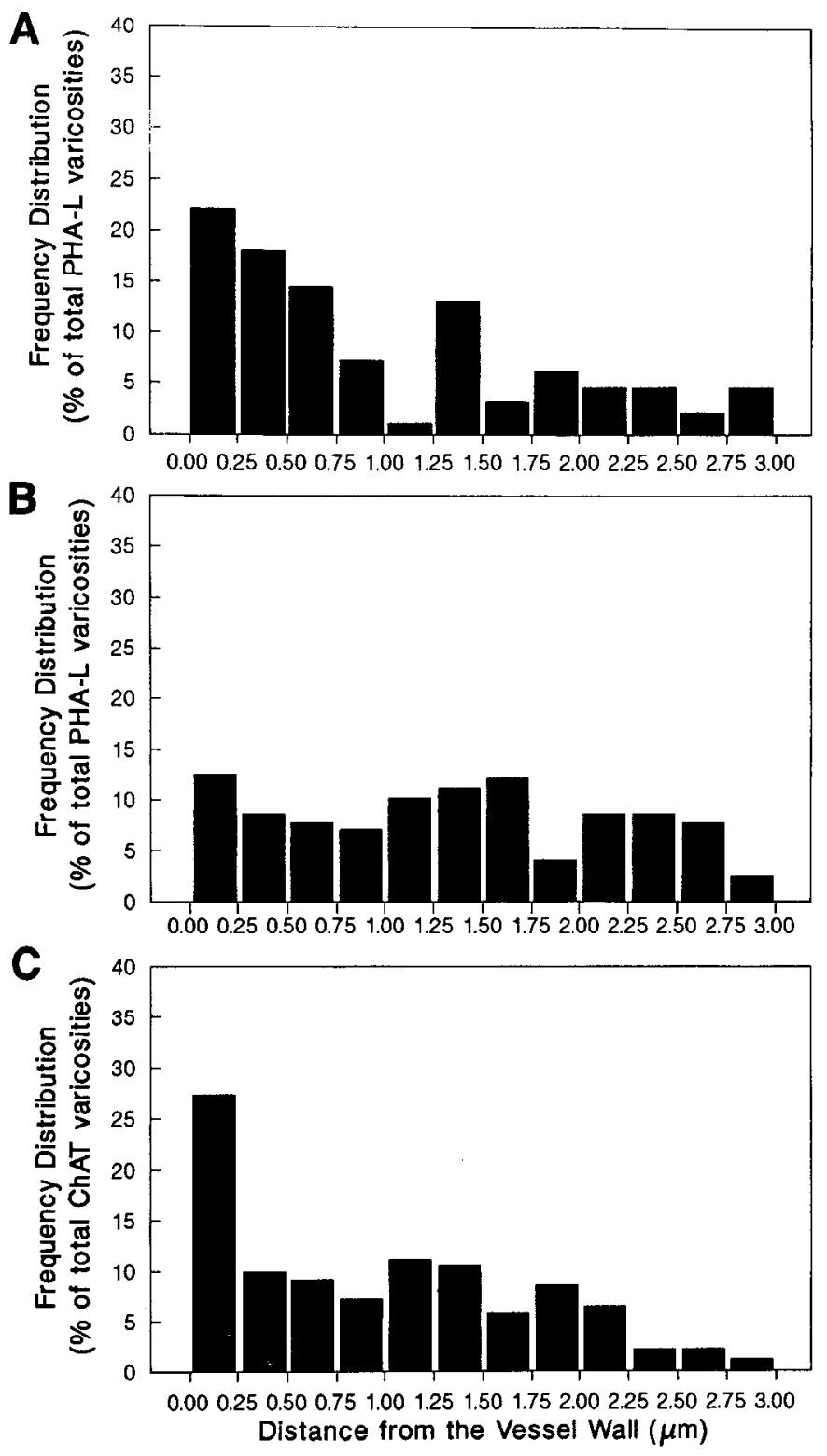

Figure 7. Histograms of the distribution of perivascular PHA-L and ChAT immunostained terminals within the $3 \mu \mathrm{m}$ interval around intracortical microvessels in fronto-parietal $(A)$ or perirhinal $(B$ and $C)$ cortex. The abscissa is divided in intervals of $0.25 \mu \mathrm{m}$ at increasing distance from the vessel basal lamina. The bars represent the number of varicosities found in each $0.25 \mu \mathrm{m}$ interval and are expressed as percentage of total PHA-L or ChAT terminals counted in each cortical area.

showed that the proportion of perivascular cholinergic terminals in the fronto-parietal cortex was about twice that of the perirhinal cortex (Table 2).

\section{Discussion}

\section{Technical considerations}

Pilot experiments, in agreement with Gerfen and Sawchenko (1984), showed that single injections of PHA-L diffused in a very small volume and labeled a limited number of SI neurons. The resulting labeling of cortical projection fibers was thus sparse and insufficient for detailed ultrastructural analysis. In contrast, the implementation of four injection sites that encompass the great majority of neurons from the anterior to the posterior aspect of the SI together with the addition of the freezethaw procedure allowed to detect dense PHA-L projection fibers in every subdivision of the ccrcbral cortex. This multisite injection procedure was found to be restricted to neurons located within the SI and to result in prominent labeling in most layers of the perirhinal-insular and entorhinal cortical area with a more circumscribed distribution of the fibers in layers IV and $V$ of the fronto-parietal cortex. Such a heterogeneous distribution is supported by previous reports (Luiten et al., 1987) and suggests that our injection and detection procedures provided a fair estimate of SI projections to the cerebral cortex.

\section{SI neurons project to cortical microvessels}

When examined in detail under light and electron microscopy, a subset of the cortical projections of PHA-L-injected SI neurons were found to be perivascular. They reached cortical penetrating arteries, small microvessels and capillaries. The finding that at least $30 \%$ of vessels corresponded in size to small arteries and microarterioles strongly suggests that these perivascular terminals may exert significant effects on vasomotricity through small resistance vessels. This contention is further supported by the fact that intracortical small arteries and arterioles have been shown to dilate or constrict in response to several vasoactive neurotransmitters (Dacey et al., 1987; Edwards et al., 1991; Sagher et al., 1993). Furthermore, since perivascular projections were studied in single sections, it is obvious that on its full length a given blood vessel is reached by a much larger number of SI terminals, a situation that is likely to increase their impact on microvascular functions. Such a vasomotor role for SI neurons appcars morc prominent in the fronto-parietal cortex as the distribution of their perivascular terminals within the $3 \mu \mathrm{m}$ perimeter around blood vessels, clearly indicated an enrichment in the immediate vicinity $(<0.25 \mu \mathrm{m})$ up to $1 \mu \mathrm{m}$ from the vessel wall. This close proximity might not suffice to confer a functional role to perivascular terminals; however, combined with the fact that such a preferential vascular association was not found for PHA-L terminals in the perirhinal cortex, an area that does not modify its blood flow in response to SI stimulation (Vaucher et al., 1995), it provides a strong morphological suhstrate for the well documented actions of SI neurons on frontoparietal blood flow (see below, and for review, Sato and Sato, 1992). Interestingly, similar intimate anatomical relationships for perivascular terminals have been associated to the effective neurogenic control of vasodilator or vasoconstrictor nerves in peripheral (Dodge et al., 1994), cerebral (Lee, 1981; Dodge et al., 1994), and intraparenchymal blood vessels (Cohen et al., 1995). In line with the fact that capillaries are approximately 10 times more numerous than arterioles (McDonald and Rasmussen, 1977), the majority of perivascular terminals reached intracortical capillaries, an observation that might be indicative of a role

$\leftarrow$

Figure 6. Perivascular PHA-L-immunolabeled terminals in the perirhinal cortex. $A$, The terminal and the axonal segment are contained within the $3 \mu \mathrm{m}$ perimeter around the vessel wall (dashed line). $B$. Two varicosities probably from the same fiber are reaching towards the capillary, only the closest varicosity is located within the $3 \mu \mathrm{m}$ perivascular perimeter. $C-D$. Perivascular PHA-L varicosities visualized in two serial electron photomicrographs are seen to establish symmetrical synaptic junctions with surrounding dendritic branches (curved arrows) and are separated from the vessel by a glial leaflet (open arrows). Scale bar: $1 \mu \mathrm{m}$. 
Table 1. Morphological features of perivascular PHA-L and ChAT nerve terminals in the cerebral cortex

\begin{tabular}{|c|c|c|c|c|}
\hline & \multicolumn{2}{|c|}{ Fronto parietal cortex } & \multicolumn{2}{|c|}{ Perirhinal cortex } \\
\hline & $\mathrm{ChAT}^{a}$ & PHA-L & ChAT & PHA-L \\
\hline$n$ & 128 & 91 & 143 & 130 \\
\hline Distance from vessel wall $(\mu \mathrm{m} \pm \mathrm{SEM})$ & $0.86 \pm 0.07$ & $0.98 \pm 0.09$ & $0.93 \pm 0.06$ & $1.34 \pm 0.07^{*}$ \\
\hline Surface area $\left(\mu \mathrm{m}^{2} \pm \mathrm{SEM}\right)$ & $0.32 \pm 0.02$ & $0.38 \pm 0.03$ & $0.31 \pm 0.02$ & $0.34 \pm 0.03$ \\
\hline Terminals within $0.25 \mu \mathrm{m}(\%)$ & 32 & 23 & 28 & 13 \\
\hline Terminals within $1 \mu \mathrm{m}(\%)$ & 60 & 62 & 56 & 36 \\
\hline Synaptic frequency $(\%)$ & 5 & 8 & 4.5 & 14 \\
\hline Synaptic incidence $(\%)$ & 14 & 23 & 9 & 28 \\
\hline
\end{tabular}

Results have been obtained as described in Materials and Methods following analysis on the number ( $n$ ) of perivascular terminals as indicated.

"Data taken from a previous study performed with identical procedures within the exact same area (Chedotal et al., 1994b).

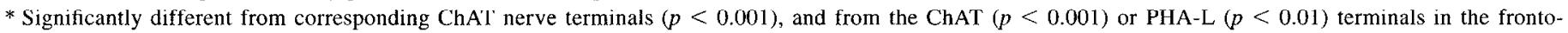
parietal cortex, as evaluated by ANOVA and the multiple comparison test of Tukey.

for SI neurons in blood-brain barrier and transport mechanisms. Nevertheless, it cannot be excluded that pericapillary terminals may also participate in flow regulation by delivering signals that could be integrated for transmission upstream to microarterioles and small arteries, as recently hypothesized in peripheral and microvascular beds (see Song and Tyml, 1993; Iadecola, 1993).

Perivascular basal forebrain terminals never established junctional contacts with the vascular or glial cells, although they could do so with adjacent dendrites. This obscrvation is suggestive of a communication via a mode of volume transmission, as already established for the functional innervation of major cerebral arteries and small pial vessels (Lee, 1981; Dodge et al., 1994) as well as for various neurotransmitters within the cerebral cortex (see Descarries et al., 1991), including ACh (Umbriaco et al., 1994). This involves diffusion of the vasoactive substance in the extracellular space before it reaches its receptor(s) in neighboring vascular, glial, and/or neuronal targets. Whether or not perivascular astrocytes, which are an integral component of the functional microvascular unit, are the primary effector of PHA-L-labeled SI terminals that abutted on glial processes rather than on endothelial or smooth muscle cells, will remain to be established. In fact, a pivotal role for perivascular astrocytes in the neurogenic control of cortical blood flow and blood-brain barrier mechanisms has been suggested previously from several characteristics of these cells (Hertz, 1992), but also from morphological evidence of neuronal-glial-vascular interactions (Chédotal et al., 1994b). It cannot be excluded, however, that the attraction exerted by cortical microvessels including perivascular astrocytes on SI terminals relies on the presence of glial and/or vascular growth factors (see Chédotal et al., 1994b) and partly fulfils a role in their survival and maintenance.

\section{Chemical nature of perivascular basalo-cortical projections}

In the fronto-parietal cortex, perivascular basalo-cortical projections shared similarities in terms of average distance from and global distribution around cortical microvessels with previously characterized perivascular cholinergic terminals (Chédotal et al., 1994b). In the perirhinal cortex, in contrast, perivascular PHA-L terminals differed from their cholinergic counterparts in their overall associations with the local microvasculature, suggesting that they are not exclusively cholinergic. This interpretation is further substantiated by the rather modest perivascular cholinergic denervation observed in perirhinal as opposed to frontoparietal cortex following SI lesion, and this in spite of the greater density of PHA-L-labeled SI projections in the perirhinal cortex.
Altogether, these findings first indicate that the cholinergic input to microvessels in the perirhinal cortex originates primarily from local interneurons (Eckenstein and Baughman, 1984; Galea et al., 1991; Chédotal et al., 1994a) while most perivascular cholinergic terminals in the fronto-parietal cortex are from the basal forebrain. Second, they suggest that a subset of PHA-L terminals studied in the present study originate from noncholinergic SI neurons, this contingent being more important in the perirhinal than the fronto-parietal cortex. Such conclusion agrees very well with previous studies claiming that while up to $80 \%$ of basalocortical projections in the fronto-parietal cortex are cholinergic, this proportion is at the most 40 to $60 \%$ in the perirhinal cortex (Rye et al., 1984; Woolf, 1991). The finding that perivascular PHA-L terminals tended to be slightly larger and more frequently engaged in synaptic contacts with neighboring dendrites than their cholinergic counterparts further supports their mixed chemical nature. The possibility exists that SI neurons containing $\gamma$-aminobutyric acid (GABA) (Frcund and Gulyas, 1991; Gritti et al., 1993), a neuromediator with vasomotor properties (for review, see Lou et al., 1987), could contribute to the pool of basalo-cortical nerve terminals associated with microvessels. Interestingly, GABA varicosities in the cerebral cortex are highly junctional and appear larger than cholinergic terminals (Houser et al., 1984), two characteristics that could partly explain the differences between PHA-L and ChAT perivascular terminals observed in the present study.

\section{Perivascular cholinergic basalo-cortical projections: functional correlates}

Cholinergic nerve terminals in the immediate vicinity of cortical microvessels had been reported previously (Eckenstein and Baughman, 1984; Armstrong, 1986; Arnerić et al., 1988) and partly or totally attributed to intrinsic bipolar cortical cholinergic neurons (Eckenstein and Baughman, 1984; Galea et al., 1991; Chédotal et al., 1994a). Our present data not only demonstrate that in the fronto-parietal cortex, the majority of these perivascular cholinergic terminals originate in the basal forebrain but also that they are proportionally twice as numerous as their counterparts in the perirhinal cortex. These findings concur with previous physiological studies that showed that cholinergic SI neurons regulate cortical blood flow primarily in the fronto-parietal cortex (for review, see Sato and Sato, 1992), most likely through muscarinic receptors localized on cortical microvessels (Estrada et al., 1983; Garcia-Villalon et al., 1991; Linville and 

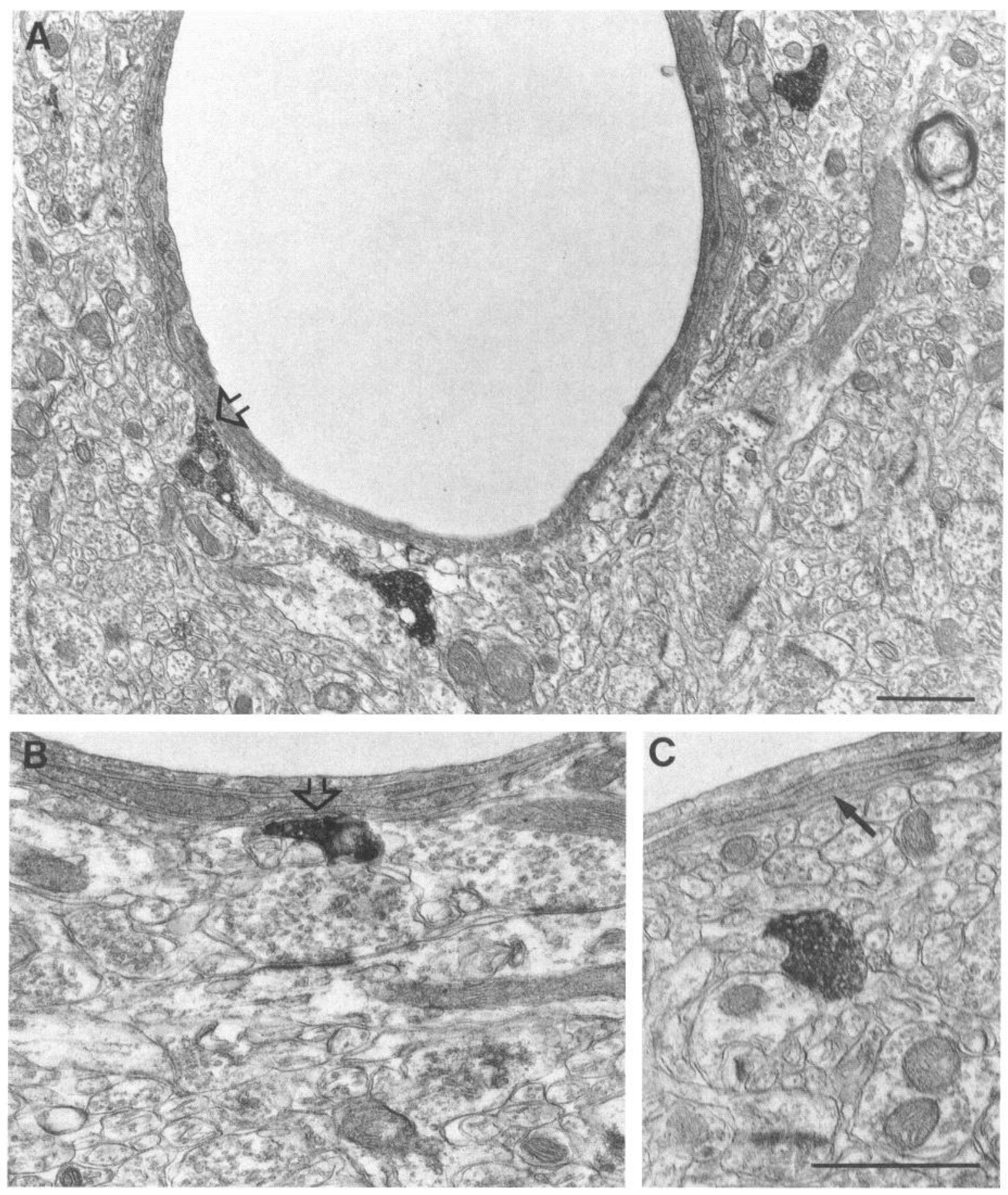

Figure 8. Perivascular ChAT immunostained terminals in the perirhinal cortex. A, Low-magnification electron photomicrograph in which three ChAT varicosities can be seen around the blood vessel. In $A$ and $B$, only a glial leaflet (open arrows) separates the terminals from the basal lamina of the vessel wall. $C$, The black arrow shows the presence of a thin pericytic extension. Scale bars: $1 \mu \mathrm{m}$.

Hamel, 1995) and/or perivascular astrocytes (Van der Zee et al., 1993; Hösli and Hösli, 1993).

The fronto-parietal and perirhinal cortices are areas where blood flow is respectively increased (for review, see Sato and Sato, 1992) or unaffected by SI stimulation (Vaucher et al., 1995). Whether this functional difference could be explained by the greater distance of PHA-L terminals from microvessels in the perirhinal as opposed to the fronto-parietal cortex, the noncholinergic nature of an important subset of these, or by the smaller proportion of perivascular cholinergic terminals in the area, remains to be established. However, it is also possible that the final mediator of the cholinergic basalo-cortical vasodilatation is produced locally in cortical cells following ACh release, as recently suggested for the cerebellar cortical vasodilatation induced by parallel fiber activation (Li and Iadecola, 1994). For instance, a role for nitric oxide (NO) has been claimed in this vasodilatory pathway (Adachi et al., 1992a; Raszkiewicz et al., 1992) and interactions between cortical perivascular cholinergic 

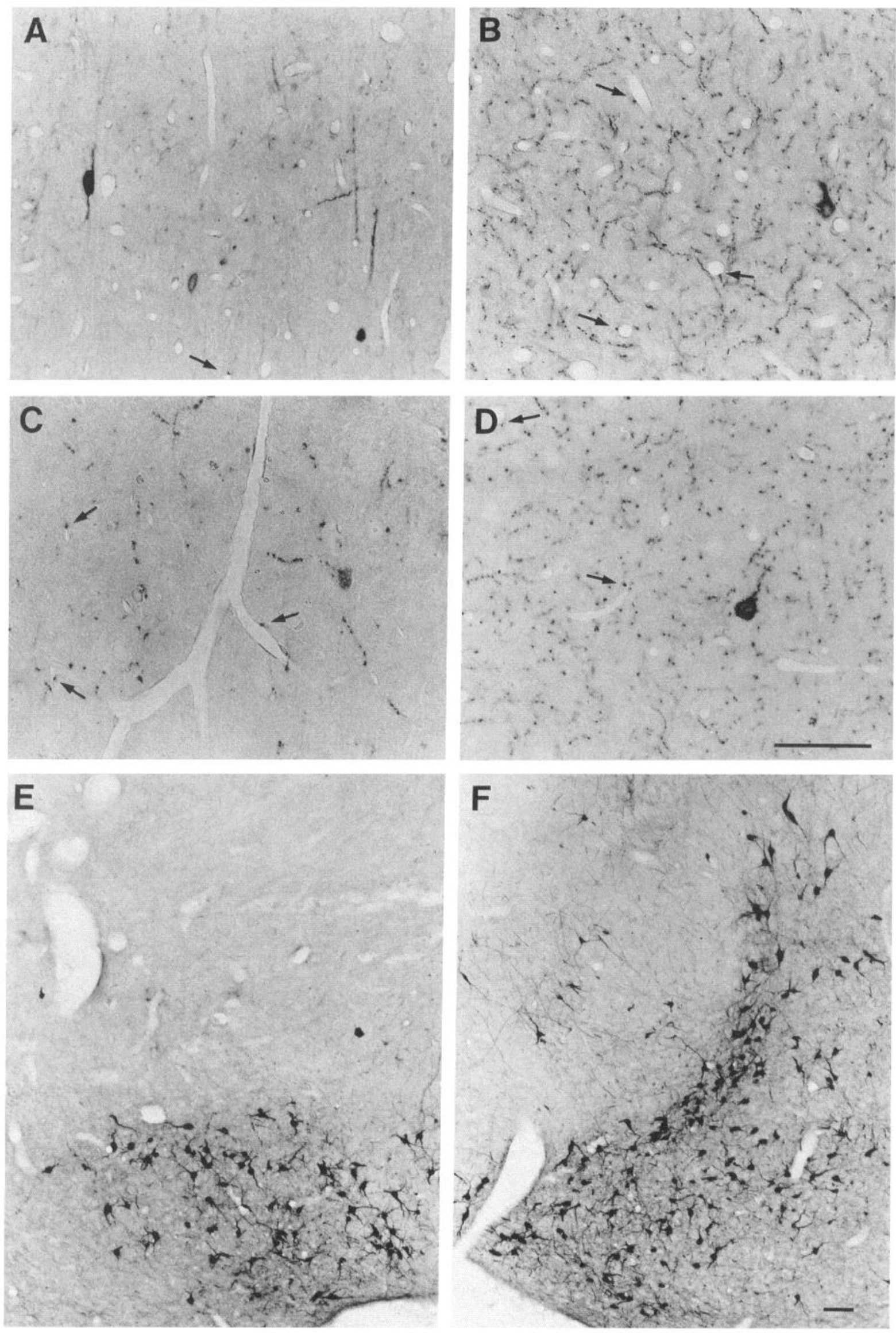


\begin{tabular}{|c|c|c|c|c|c|}
\hline $\begin{array}{l}\text { Cortical } \\
\text { subdivision }\end{array}$ & Side & $\begin{array}{l}\text { Total ChAT } \\
\text { terminals }\end{array}$ & Decreasc $\%$ & $\begin{array}{l}\text { Perivascular } \\
\text { ChAT } \\
\text { terminals }\end{array}$ & Decrease $\%$ \\
\hline \multirow[t]{2}{*}{ Fronto-parietal } & Control & $448 \pm 20$ & & $10.7 \pm 1.5$ & \\
\hline & Lesion & $198 \pm 33^{* * * *}$ & $\begin{array}{l}55 \perp 7.8 \\
(31-74)\end{array}$ & $4.0 \perp 0.9^{* *}$ & $\begin{array}{l}63 \pm 6.8 \\
(47-75)\end{array}$ \\
\hline \multirow[t]{2}{*}{ Perirhinal } & Control & $680 \pm 50$ & & $8.4+0.9$ & \\
\hline & Lesion & $501 \pm 60$ & $\begin{array}{l}26 \pm 7.9 \\
(7-43)\end{array}$ & $6.1 \pm 0.9 *$ & $\begin{array}{l}35 \pm 13.2 \\
(0-50)\end{array}$ \\
\hline
\end{tabular}

Data are expressed as mean \pm SEM $(n=5)$ of the amount of ChAT-immunolabelled terminals counted in an area of $0.2 \mathrm{~mm}^{2}$ of cortical surface in two individual semithin sections for each rat. The range of percent decrease among the rats is given within parentheses.

$* * * p<0.001 ; * * p<0.005$, and * $p<0.05$ (in this case $n=4$ ) by Student's $t$ test.

SI terminals and NO neurons have recently been identified (Vaucher et al., 1995) and could take place in order to elicit the proper vasodilatory response (for review, see Iadecola, 1993; Iadecola et al., 1994). Further functional and pharmacological studies will be required to support such hypothesis, but it is clear that within the $3 \mu \mathrm{m}$ perimeter around blood vessels, perivascular terminals interact with other neuronal elements that could lead to the release of the primary vasoactive effector(s). The role of perivascular SI projections in the cortical areas where blood flow is unaffected by SI stimulation, although not exclusive to these areas, might be more closely related to the regulation of the blood-brain barrier. Such a possibility is supported by the documented association of perivascular ChAT terminals with capillaries (Arnerić et al., 1988; Chédotal et al., 1994b, this study) and the presence of receptors for various neurotransmitters including ACh on endothelial cells (Spatz et al., 1989; Xu et al., 1992).

\section{Relevance to Alzheimer disease}

In humans, cholinergic innervation of the neocortex originates almost exclusively in the nucleus basalis of Meynert in the basal forebrain (Ramon-Moliner and Nauta, 1966; Mesulam and Geula, 1988). It has been suggested that such cholinergic nerve terminals associate with intracortical microvessels, thus providing an additional mechanism through which $\mathrm{ACh}$ could influence cortical activity (Mesulam et al., 1992). Compelling evidence has recently accumulated that indicates hiochemical and morphological changes in brain microvasculature in Alzheimer disease (for review, see Kalaria, 1992). More specifically, a denervation microangiopathy together with microvascular pathological changes including basal lamina thickening, $\beta$-amyloid deposit, and multiple capillary distortion (Perlmutter and Chang Chui, 1990; Scheibel et al., 1987; Vinters et al., 1994; Buée et al., 1994) have been consistently documented. Whether these vascular and neuronal events occur independently or whether the neuronal degeneration is a consequence of vascular dysfunction (Scheibel et al., 1987; de la Torre and Mussivand, 1993) remains to be established. In view of our present findings and the recent reports on the fate and plasticity of cerebrovascular innervation in aging (Andrews and Cowen, 1994), it is tempting to speculate that if perivascular cholinergic innervation of cortical microvessels degenerates in $\mathrm{AD}$, this could most likely elicit abnormalities in cortical microperfusion and/or blood-brain barrier functions, two features well documented in AD (for review, Kalaria, 1992).

In conclusion, we have demonstrated the existence of projection fibers between basal forebrain neurons and cortical microarterioles and capillaries, and have shown that a large proportion of these terminals in the fronto-parietal cortex originate from cholinergic SI neurons. The topometric results together with those of selective SI lesion further suggest that noncholinergic SI neurons also contribute to the neurogenic input to cortical microvessels, and more so in the perirhinal subdivision. Further, the data suggest that the microvascular bed in the fronto-parietal cortex might be more closely influenced by basal forebrain neurons than that of the perirhinal cortex, in agreement with physiological blood flow studies following stimulation of SI neurons. It has been suggested that a denervation microangiopathy occurs in senile dementia of the Alzheimer's type (Scheibel et al., 1987). Our study potentially points to the involvement of such neurovascular cholinergic terminals originating from the basal forebrain in this microvascular denervation process. However, such conclusion awaits further studies in human brain tissue.

\section{References}

Adachi T, Biesold D, Inanami O, Sato A (1990a) Stimulation of nucleus basalis of Meynert and substantia innominata produces widespread increases in cerebral blood flow in the frontal, parietal and occipital cortices. Brain Res 514:163-166.

Adachi T, Inanami O, Ohno K, Sato A (1990b) Responses of regional cerebral blood flow following focal electrical stimulation of the nucleus basalis of Meynert and the medial septum using the $\left[{ }^{14} \mathrm{C}\right]$ iodoantipyrine method in rats. Neurosci Lett 112:263-268.

Adachi T, Inanami O, Sato A (1992a) Nitric oxide (NO) is involved in increased cerebral cortical blood flow following stimulation of the nuclcus basalis of Mcynert in anesthetized rats. Neurosci Lett 139: 201-204.

Adachi T, Baramidze DG, Sato A (1992b) Stimulation of the nucleus

$\leftarrow$

Figure 9. Effects of substantia innominata lesion on the cholinergic innervation of cortical microvessels. In semithin sections (upper four panels), the density of cortical cholinergic nerve terminals including those associated with intrinsic microvessels is reduced on the lesioned $(A$ and $C$ ) as compared to the control side $(B$ and $D$ ) and more so in the fronto-parietal than in the perirhinal cortex (upper and middle panels, respectively; see Table 2 for quantitative analysis). Note that some perivascular terminals remain (arrows in $A$ and $C$ ), and particularly in the perirhinal cortex following effective ibotenic acid lesion of ChAT-immunostained SI neurons $(E)$. Control side $(F)$. Scale bars: $50 \mu \mathrm{m}(A-D)$; $100 \mu \mathrm{m}(E$ and $F)$. 
basalis of Meynert increases cerebral blood flow without influencing diameter of the pial artery in rats. Neurosci Lett 143:173-176.

Andrews TJ, Cowen T (1994) In vivo infusion of NGF induces the organotypic regrowth of perivascular nerves following their atrophy in aged rats. J Neurosci 14(5):3048-3058.

Armstrong DM (1986) Ultrastructural characterization of choline acetyltransferase-containing neurons in the basal forebrain of rat: evidence for a cholinergic innervation of intracerebral blood vessels. J Comp Neurol 250:81-92.

Arnerić SP, Honig MA, Milner TA, Greco S, Iadecola C, Reis DJ (1988) Neuronal and endothelial sites of acetylcholine synthesis and release associated with microvessels in rat cerebral cortex: ultrastructural and neurochemical studies. Brain Res 454:11-30.

Arnerić SP (1989) Cortical cerebral blood flow is modulated by cholinergic basal forebrain neurons: effects of ibotenic acid lesions and electrical stimulation. In: Neurotransmission and cerebrovascular function, Vol I (Seylaz J, Mackenzie ET, eds), pp 381-384. Amsterdam: Elsevier.

Bartus RT, Flicker C, Dean RL, Pontecorvo M, Figueiredo JC, Fisher SK (1985) Selective memory loss following nucleus basalis lesions: long term behavioral recovery despiste persistent cholinergic deficiencies. Pharmacol Biochem Behav 23:125-135.

Beaudet A, Sotelo C (1981) Synaptic remodeling of serotonin axon terminals in rat agranular cerebellum. Brain Res 206:305-329.

Biesold D, Inanami O, Sato A, Sato Y (1989) Stimulation of the nucleus basalis of Meynert increases cerebral cortical blood flow in rats. Neurosci Lett 98:39-44.

Buée L, Hof PR, Bouras C, Delacourte A, Perl DP, Morrison JH, Fillit HM (1994) Pathological alterations of the cerebral microvasculature in Alzheimer's disease and related dementing disorders. Acta Neuropathol 87:469-480.

Chédotal A, Cozzari C, Faure MP, Hartman BK, Hamel E (1994a) Distinct choline acetyltransferase (ChAT) and vasoactive intestinal polypeptide (VIP) bipolar neurons project to local blood vessels in the rat cerebral cortex. Brain Res 646:181-193.

Chédotal A, Umbriaco D, Descarries L, Hartman BK, Hamel E (1994b) Light and electron microscopic immunocytochemical analysis of the neurovascular relationships of choline acetyltransferase and vasoactive intestinal polypeptide nerve terminals in the rat cerebral cortex. J Comp Ncurol 343:57-71.

Cohen Z, Ehret M, Maître M, Hamel E (1995) Ultrastructural analysis of tryptophan hydroxylase immunoreactive nerve terminals in the rat cerebral cortex and hippocampus: their associations with local blood vessels. Neuroscience 66:555-569.

Coyle JT, Price DL, De Long MR (1983) Alzheimer's disease: a disorder of cortical cholinergic innervation. Science 219:1184-1190.

Dacey RG Jr, Bassett JE (1987) Cholinergic vasodilation of intracerebral arterioles in rats. Am J Physiol 253:H1253-H1260.

Dauphin F, Lacombe P, Sercombe R, Hamel E, Seylaz J (1991) Hypercapnia and stimulation of the substantia innominata increase rat frontal cortical blood flow by different cholinergic mechanisms. Brain Res 553:75-83.

De la Torre JC, Mussivand T (1993) Can distrubed brain microcirculation cause Alzheimer's disease? Neurol Res 15:146-153.

Divac I (1975) Magnocellular nuclei of the basal forebrain project to the neocortex, brainstem, and olfactory bulb. Review of some functionnal correlates. Brain Res 93:385-398.

Dodge JT, Bevan RD, Bevan JA (1994) Comparison of density of sympathetic varicosities and their closeness to smooth muscle cells in rabbit middle cerebral and ear arteries and their branches. Circ Res 75:916-925.

Eckenstein F, Baughman RW (1984) Two types of cholinergic innervation in cortex, one co-localized with vasoactive intestinal polypeptide. Nature 309:153-155.

Edwards RM, Stack EJ, Trizna W (1991) Calcitonin gene-related peptide stimulates adenylate cyclase and relaxes intracerebral arterioles. J Pharmacol Exp Ther 257:1020-1024.

Estrada C, Hamel E, Krause DN (1983) Biochemical evidence for cholinergic innervation of intracerebral blood vessels. Brain Res 266: $261-270$

Freund TF, Gulyas AI (1991) Gabaergic interneurons containing calbindin $\mathrm{d} 28 \mathrm{k}$ or somatostatin are major targets of gabaergic basal forebrain afferents in the rat neocortex. J Comp Neurol 314:187-199.

Galea E, Fernandez-Shaw C, Triguero D, Estrada C (1991) Choline acetyltransferase activity associated with cerebral cortical microves- sels does not originate in basal forebrain neurons. $J$ Cereb Blood Flow Metab 1 1:875 878.

Garcia-Villalon AL, Krause DN, Ehlert FJ, Duckles SP (1991) Heterogeneity of muscarinic receptor suptypes in cerebral blood vessels. J Pharmacol Exp Ther 258:304-310.

Gerfen CR, Sawchenko PE (1984) An anterograde neuroanatomical tracing method that shows the detailed morphology of neurons, their axons and terminals: immunohistochemical localization of an axonally transported plant lectin, Phaseolus vulgaris leucoagglutinin (PHA-L). Brain Res 290:219-238.

Gomi S, Gotoh F, Ishihara N, Tanaka K, Ishikawa Y, Takashima S, Mihara B (1991) Effects of lesioning of the substantia innominata on autoregulation of local cerebral blood flow in rats. J Cereb Blood Flow Metab 11:66-71.

Gritti I, Mainville L, Jones BE (1993) Codistribution of GABA- with acetylcholine-synthesizing neurons in the basal forebrain of the rat. J Comp Neurol 329:438-457

Hertz L (1992) Autonomic control of neuronal-astrocytic interactions, regulating metabolic activities and ion fluxes in the CNS. Brain Res Bull 29:303-313.

Hösli E, Hösli L (1993) Receptors for neurotransmitters on astrocytes in the mammalian central nervous system. Prog Neurobiol 40:477506.

Houser CR, Vaughn JE, Hendry SHC, Jones EG, Peters A (1984) GABA neurons in the cerebral cortex. In: Cerebral cortex, Vol 2 (Jones EG, Peters A, eds), pp 63-89. New York: Plenum.

Iadecola C (1993) Regulation of the cerebral microcirculation during neural activity: is nitric oxide the missing link? Trends Neurosci 16: 206-214.

Iadecola C, Beitz AJ, Renno W, Xu X, Mayer B, Zhang F (1993) Nitric oxide synthase-containing neural processes on large cerebral arteries and cerebral microvessels. Brain Res 606:148-155.

Iadecola C, Pelligrino DA, Moskowitz MA, Lassen NA (1994) Nitric oxide synthase inhibition and cerebrovascular regulation. J Cercb Blood Flow Metab 14:175-192.

Kalaria RN (1992) The blood-brain barrier and cerebral microcirculation in Alzheimer disease. Cerebrovasc Brain Metab Rev 4:226-260.

Kurosawa M, Sato A, Sato Y (1989) Well-maintained responses of acetylcholine release and blood flow in the cerebral cortex to focal electrical stimulation of the nucleus basalis of Meynert in aged rats Neurosci Lett 100:198-202.

I acombe P, Sercombe R, Correze JL, Philipson V, Mackenzie ET, Seylaz J (1987) Cortical vasodilatation induced by electrical stimulation of the substantia innominata in anesthetized rats. J Cereb Blood Flow Metab 7(Suppl 1):S393.

Lacombe P, Sercombe R, Verrecchia C, Philipson V, MacKenzie ET, Seylaz J (1989) Cortical blood flow increases induced by stimulation of the substantia innominata in the unasthethetized rat. Brain Res 491: $1-14$.

Lee TJ-F (1981) Ultrastructural distribution of vasodilator and constrictor nerves in cat cerebral arteries. Circ Res 49:971-979.

Leveugle B, Yang C, Eisler J, Bouras C, Hof PR, Fillit HM (1994) Microvascular pathologic changes in hippocampal formation in Alzheimer disease. Soc Neurosci Abstr 20:1033.

Li J, Iadecola C (1994) Nitric oxide and adenosine mediate vasodilation during functional activation in cerebellar cortex. Neuropharmacology 33:1453-1461.

Linville DG, Hamel E (1995) Pharmacological characterization of muscarinic acetylcholine binding sites in human and bovine cerebral microvessels. Naunyn Schmiedebergs Arch Pharmacol 352:179-186.

Linville DG, William S, Arneric SP (1993a) Basal forebrain control of cortical cerebral blood flow is independant of local cortical neurons. Brain Res 622:26-34.

Linville DG, William S, Raszkiewicz JL, Arneric SP (1993b) Nicotinic agonists modulate basal forebrain control of cortical cerebral blood flow in anesthetized rats. J Pharmacol Exp Ther 267:440-448.

Lou HC, Edvinsson L, MacKenzie ET (1987) The concept of coupling blood flow to brain function: revision required? Ann Neurol 22:289297.

Luiten PGM, Gaykema RPA, Traber J, Spencer DG Jr (1987) Cortical projection patterns of magnocellular basal nucleus subdivisions as revealed by anterogradely transported Phaseolus vulgaris leucoagglutinin. Brain Res 413:229-250.

McDonald DM, Rasmussen GL (1977) An ultrastructural analysis of 
neurites in the basal lamina of capillaries in the chinchilla cochlear nucleus. J Comp Neurol 173:475-496.

Mesulam M-M, Geula C (1988) Nucleus basalis (Ch4) and cortical cholinergic innervation of the human brain: morphology, cytochemistry, connectivity and some behavioral implications. J Comp Neurol 275:216-240.

Mesulam MM, Mufson EJ, Wainer BH, Levey Al (1983) Central cholinergic pathways in the rat: an overview based on an alternative nomenclature (chl-ch6). Neuroscience 10:1185-1201.

Mesulam MM, Hersh LB, Mash DC, Geula C (1992) Differential cholinergic innervation within functionnal subdivisions of the human cerebral cortex: a choline acetyltransferase study. I Comp Neurol 318: 316-328.

Paxinos G, Watson C (1986) The rat brain in stereotaxic coordinates. 2nd ed. Sydney: Academic.

Perlmutter LS, Chui HC (1990) Microangiopathy, the vascular basement membrane and Alzheimer's disease: a review. Brain Res Bull 24:677-686.

Peruzzi P, Lacombe P, Moro V, Vaucher E, Levy F, Seylaz J (1993) The cerebrovascular effects of physostigmine are not mediated through the substantia innominata. Exp Neurol 122:319-326.

Raczkiewicz JL, Linville DG, Kerwin JJ Jr, Wagenaar F, Arneric SP (1992) Nitric oxide synthase is critical in mediating basal forebrain regulation of cortical cerebral circulation. J Neurosci Res 33:129135.

Ramon-Moliner E, Nauta WJH (1966) The isodendritic core of the brainstem. J Comp Neurol 126:311-336.

Rye DB, Wainer BH, Mesulam MM, Mufson EJ, Saper CB (1984) Cortical projections arising from the basal forebrain: a study of cholinergic and non-cholinergic components employing combined retrograde tracing and immunohistochemical localization of choline acetyltransferase. Neuroscience 13:627-643.

Sagher O, Zhang X-Q, Szeto W. Thai QA, Jin Y, Kassell NF, Lee KS (1993) Live computerized videomicroscopy of cerebral microvessels in brain slices. J Cereb Blood Flow Metab 13:676-682.

Sato A, Sato Y (1992) Regulation of regional cerebral blood flow by cholinergic fibers originating in the basal forebrain. Neurosci Res 14 242-274.
Scheibel AB, Duong T, Tomiyasu U (1987) Denervation microangiopathy in senile dementia, Alzheimer type. Alzheimer Dis Assoc Disord 1:19-37.

Song II, Tyml K (1993) Evidence for sensing and integration of biological signals by the capillary network. Am Physiol Soc HI235H1242.

Spatz M, Bacic F, McCarron RM, Merkel N, Uematsu S, Long DM, Bembry J (1989) Cholinergic and histaminergic receptors in cultured endothelium derived from human cerebral microvessels. In: Neurotransmission and cerebrovascular function, Vol I (Seylaz J. MacKenzie ET, eds), pp 105-108. Amsterdam: Excerpta Medica.

Umbriaco D, Watkins KC, Descarries L. Cozzari C. Hartman BK (1994) Ultrastructural and morphometric features of the acetylcholine innervation in adult rat parietal cortex: an electron microscopic study in serial sections. J Comp Neurol 348:351-373.

Van der Zee EA, De Jong GI, Strosberg AD, Luiten PGM (1993) Muscarinic acetylcholine receptor-expression in astrocytes in the cortex of young and aged rats. Glia 8:42-50.

Vaucher E, Hamel E (1994) Morphological evidence for innervation of cortical microvessels by cholinergic basal forebrain neurons. Soc Neurosci Abstr 20:78.

Vaucher E, Borredon J, Seylaz J, Lacombe P (1995) Autoradiographic distribution of cerebral blood flow increases elicited by stimulation of the nucleus basalis magnocellularis in the unanesthetized rat. Brain Res, in press.

Vaucher E, Linville DG, Grégoire L, Edvinsson L. Hartman BK, Hamel E (1995) Cholinergic basal forebrain neurons project to microvessels and nitric oxide synthase (NOS) neurons in the rat cerebral cortex. $J$ Cereb Blood Flow Metab 15(Suppl 1):S449.

Vinters HV, Secor DL, Read SL, Frazee JG, Tomiyasu U, Stanley TM, Ferreiro JA, Akers M-A (1994) Microvasculature in brain biopsy specimens from patients with Alzheimer's disease: an immunohistochemical and ultrastructural study. Ultrastruct Pathol 18:333-348.

Woolf NJ (1991) Cholinergic systems in mammalian brain and spinal cord. Prog Neurobiol 37:475-524.

Xu J, Qu Z-X, Moore SA, Hsu CY, Hogan EL (1992) Receptor-linked hydrolysis of phosphoinositides and production of prostacyclin in cerebral endothelial cells. J Neurochem 58:1930-1935. 